Article

\title{
Breakdown Voltage and Its Influencing Factors of Thermally Aged Oil-Impregnated Paper at Pulsating DC Voltage
}

\author{
Jing Zhang ${ }^{1}$, Feipeng Wang ${ }^{1, *}$, Jian $\mathrm{Li}^{1}{ }^{1, *}$, Hehuan $\operatorname{Ran}^{1}{ }^{1}$, Xudong $\mathrm{Li}^{1}$ and Qiang $\mathrm{Fu}^{2}$ \\ 1 State Key Laboratory of Power Transmission Equipment \& System Security and New Technology, \\ School of Electrical Engineering, Chongqing University, Chongqing 400044, China; \\ zhangjing2012@cqu.edu.cn (J.Z.); ranhehuan@cqu.edu.cn (H.R.); lixudong@cqu.edu.cn (X.L.) \\ 2 Electric Power Research Institute of Guangdong Power Grid Co., Ltd., Guangzhou 510080, China; \\ 13926402226@163.com \\ * Correspondence: fpwang@cqu.edu.cn (F.W.); lijian@cqu.edu.cn (J.L.); \\ Tel.: +86-23-6511-1795 (F.W.); +86-23-6510-2430 (J.L.)
}

Academic Editors: Akhtar Kalam and Tapas Mallick

Received: 27 July 2017; Accepted: 12 September 2017; Published: 15 September 2017

\begin{abstract}
Breakdown strength is an important electrical property of insulating paper. Oil-impregnated paper of various aging states was prepared. Its breakdown voltage was then measured at pulsating direct current (DC) voltage with various ripple factors, and alternating current (AC) and DC voltage for comparison, respectively. The AC breakdown voltage is the smallest, and pulsating DC $(r=1 / 5)$ breakdown voltage is the greatest before the paper reaches its end of life. A dielectric model was adopted to investigate the difference in magnitude of breakdown voltage at different voltage waveforms. Meanwhile, it was found that breakdown voltage fluctuated and even increased occasionally during the thermal aging process, and a somewhat opposite changing tendency versus aging time was observed for breakdown voltage at DC voltage and pulsating DC voltage with small ripple factors $(r=1 / 5$ and 1/3), compared with AC voltage. The degree of polymerization (DP) and moisture content of the paper were measured, and the characteristics of the pores and cracks of the paper were obtained to investigate the possible influencing factors of breakdown voltage at different aging states. The results showed that the moisture content, oil absorption ability associated with pores and cracks of paper, and the damage to paper structure all contributed to the variation of the breakdown voltage versus aging time, while the importance of their influence differed as the aging state of paper varied.
\end{abstract}

Keywords: breakdown voltage; pulsating DC voltage; thermal aging; double-composite dielectric model; oil absorption ability; oil-impregnated paper

\section{Introduction}

Power transformers are essential to power transmission networks [1]. As the insulating medium of power transformers, oil-impregnated paper (OIP) degrades under interaction with heat, moisture, oxygen, and acids [2,3]. Among those aging factors, heat is the main cause of insulation aging, and thus reduces its mechanical strength and electrical performance. Therefore, condition assessment of OIP using its dielectric and physicochemical characteristics is essential to the safe operation, planned maintenance, and replacement of transformers [4]. Breakdown voltage is an important property of insulating paper, and thermal aging is the main form of OIP aging. Investigation into the breakdown characteristics of thermally aged OIP is conducive to understanding the influencing mechanism of aging on its insulating performance. 
Meanwhile, as the direct current transmission system is developing rapidly, the converter transformer has attracted much attention by researchers. The valve-side windings in a converter transformer withstand the voltage of complex waveforms [5]. The turn-to-ground insulation of the valve-side wingdings withstands pulsating DC voltage [5,6], also known as combined AC-DC voltage or AC and DC combined voltages [7-10]. The breakdown characteristics of OIP at pulsating DC voltage show many differences compared with that at AC voltage [6]. Therefore, it is necessary to investigate the breakdown voltage of aged OIP at this type of voltage waveform.

The breakdown voltage of OIP or oil-paper insulation has been widely studied at various voltage waveforms, including AC voltage [11,12], DC voltage [13,14], impulse voltage [12,15-18], and pulsating DC voltage $[6,19,20]$. In [6], the breakdown voltage of OIP at pulsating DC voltage (with a ripple factor of 1 and 1/3) was measured. It was found that the pulsating DC breakdown voltage lies between AC and DC breakdown voltage when temperature varies from $60^{\circ} \mathrm{C}$ to $110^{\circ} \mathrm{C}$. Chen et al. [20] theoretically calculated the distribution of electric field strength for the oil-paper insulation when it was subjected to pulsating DC voltage. Experiments showed that the breakdown voltage reaches its maximum value when a small ratio of AC component is contained in the applied voltage, and this maximum value shows no significant difference compared with that at individual DC voltage. The papers used were all unaged insulating papers. There are few publications investigating the breakdown voltage of thermally aged paper at AC voltage [12,21,22], let alone investigation into that at pulsating DC voltage. Sun et al. [12] found the AC breakdown voltage of thermally aged OIP increases with the increased duration of thermal aging. The increase in breakdown voltage was attributed to the emergence of micro globules and the breakdown of the cellulose fibers, which improved the electric field distribution in the OIP. Liao et al. [21] measured the AC breakdown strength of oil-impregnated pressboards thermally aged in both mineral and vegetable insulating oil at $110{ }^{\circ} \mathrm{C}$. The breakdown voltage of the pressboard fluctuates with the increase of thermal aging duration and no clear correlation with degree of polymerization (DP) was found. Tang et al. [22] investigated the AC breakdown voltage of thermally aged paper in both mineral and vegetable insulating oil at $90{ }^{\circ} \mathrm{C}, 110{ }^{\circ} \mathrm{C}$, and $130{ }^{\circ} \mathrm{C}$, and no pronounced correlation between AC breakdown voltage with the DP of the paper or thermal aging temperature was observed. The breakdown voltage firstly exhibited a small decrease but then increased during the thermal aging process. It remains to be seen, however, whether the breakdown voltage of thermally aged OIP at pulsating DC voltage exhibits the same changing tendency as that at AC voltage.

This work aims at investigating the breakdown voltage of thermally aged OIP at pulsating DC voltage and the possible influencing factors. Firstly, the Kraft insulating paper was thermally aged in oil at a temperature of $120^{\circ} \mathrm{C}$ and $130^{\circ} \mathrm{C}$. Next, breakdown voltage of paper of different aging states at pulsating DC voltage was measured. For comparison, identical experiments were carried out at AC and DC voltage. Lastly, the difference in magnitude of breakdown voltage at those three kinds of voltage waveforms was interpreted with the double-composite dielectric model. The moisture content of the paper and oil absorption ability associated with the pores and cracks of the paper, and the structural damage of the paper were adopted to explain the changing tendency of breakdown voltage versus aging time.

\section{Experiments}

\subsection{Accelerated Thermal Aging Experiments}

OIP of different aging states were obtained through accelerated thermal aging experiments. The naphthenic-based mineral oil Karamay 25\# from Petrolchina and Kraft insulating paper from Taizhou Xinyuan Electrical Equipment Co., Ltd., China were used to conduct the experiments. The paper has a thickness of $0.13 \mathrm{~mm}$ and a diameter of $80 \mathrm{~mm}$, respectively. To simulate the processing procedures of oil-paper in an actual transformer and to control the initial state of experimental samples, the oil and paper were separately degassed and dehydrated in a vacuum drying chamber at $50 \mathrm{~Pa} / 80^{\circ} \mathrm{C}$ for 
$48 \mathrm{~h}$. Then the paper went through an oil impregnation process for $48 \mathrm{~h}$ at $50 \mathrm{~Pa} / 60^{\circ} \mathrm{C}$. Thereafter, they were transferred into a stainless steel container, with the ratio of oil to paper being 10:1 by weight. Figure 1 illustrates the sample processing procedure for accelerated thermal aging. Lastly, the sealed containers were put into an oven, which was heated to $120^{\circ} \mathrm{C}$ or $130{ }^{\circ} \mathrm{C}$. Table 1 lists the thermal aging temperatures and corresponding aging times. The temperature for accelerated thermal aging experiment was determined according to the following two principles. Firstly, the temperature should not be too low (say below $90^{\circ} \mathrm{C}$ ), as a low temperature results in a very long time to accomplish the thermal aging experiment. Secondly, the temperature should not be too high, as a high temperature may exceed the flash point of the insulating oil (say above $140^{\circ} \mathrm{C}$ ). Based on the two principles and the thermal aging temperatures adopted by other researchers, $120^{\circ} \mathrm{C}$ and $130{ }^{\circ} \mathrm{C}$ were finally chosen for the thermal aging experiment.

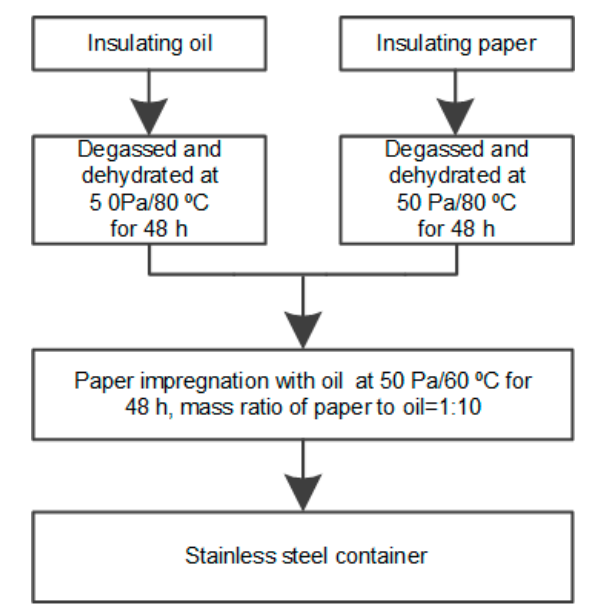

Figure 1. Sample processing procedure.

Table 1. Thermal aging temperature and corresponding aging time.

\begin{tabular}{cc}
\hline Thermal Aging Temperatures $\left({ }^{\circ} \mathrm{C}\right)$ & Aging Time (Day) \\
\hline 120 & $2,4,7,10,22,35,60,120,180$ \\
130 & $0.5,2,4,7,10,22,35,60,90$ \\
\hline
\end{tabular}

At each due time, one container was removed from the aging oven to obtain aged OIP samples for the following test items: breakdown voltage, moisture content, DP, nitrogen gas adsorption and desorption tests, and scanning electron microscope (SEM) test. The moisture content and DP of paper were measured to see if it was strongly correlated with the variation of breakdown voltage of OIP. Measurement of the moisture content of OIP was accomplished with a Karl-Fischer coulometric titrator (Metrohm moisture meter 851 and oven 885, Herisau, Switzerland), following IEC 60814. Measurement of the DP of the paper was conducted according to IEC 60450. The gas adsorption and desorption test, and SEM test were conducted to investigate the mesoporous distribution, and pores and cracks of the paper during the thermal aging process, respectively.

\subsection{Experimetnal Setup for Breakdown Voltage Test}

Figure 2 illustrates the experimental setup for the breakdown voltage test. It consists of a power source, an oil vessel, an electrode system, and some measurement instruments. The power source included a function generator and a high voltage power amplifier (TREK $50 \mathrm{kV} / 12 \mathrm{~mA}$ ). The function generator provides the required voltage signal, and the high voltage power amplifier raises the voltage to the required level. An asymmetric electrode system was designed [23] to measure the breakdown voltage of OIP, as depicted in Figure 3. 


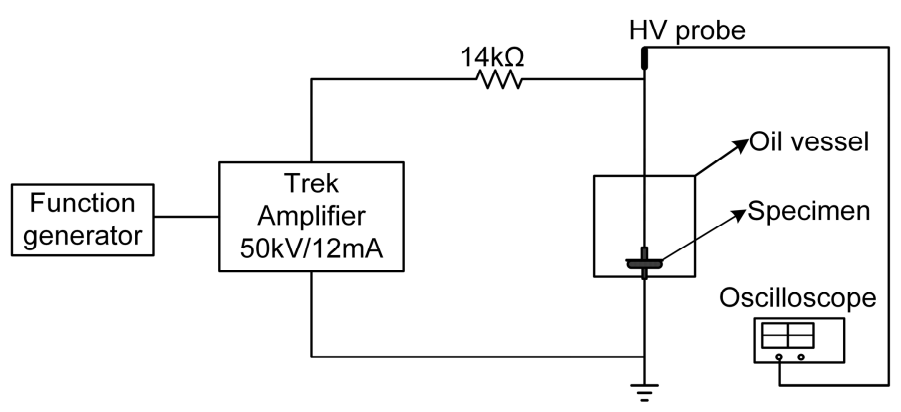

Figure 2. The setup of breakdown voltage test at different voltage waveforms.

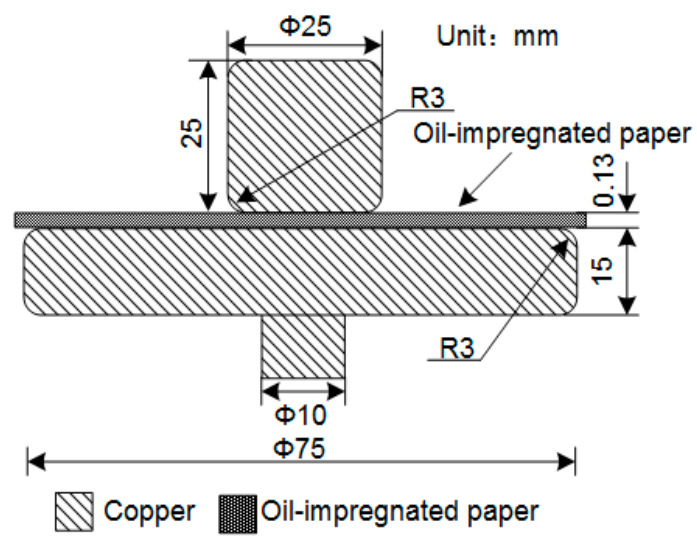

Figure 3. The electrode system.

\subsection{Breakdown Voltage Test}

For OIP of each aging time, breakdown voltages of 10 specimens were measured to obtain 10 breakdown voltage data at room temperature. For the convenience of description, the peak value of the voltage was recorded and considered to be the breakdown voltage when the OIP broke down. The positive pulsating DC voltage with various ripple factors was applied to the OIP during the test, respectively. The ripple factor $r$ is the ratio of the amplitude of the AC component $U_{A C}$ to the magnitude of the DC component $U_{D C}$, as is shown in Equation (1). Figure 4 illustrates the typical waveform for pulsating DC voltage with a ripple factor of 1 . In this work, pulsating DC voltages with an $r$ of $1 / 5,1 / 3$, and 1 were chosen to investigate the breakdown voltage of OIP at pulsating DC voltage [5].

$$
r=\frac{U_{A C}}{U_{D C}}
$$

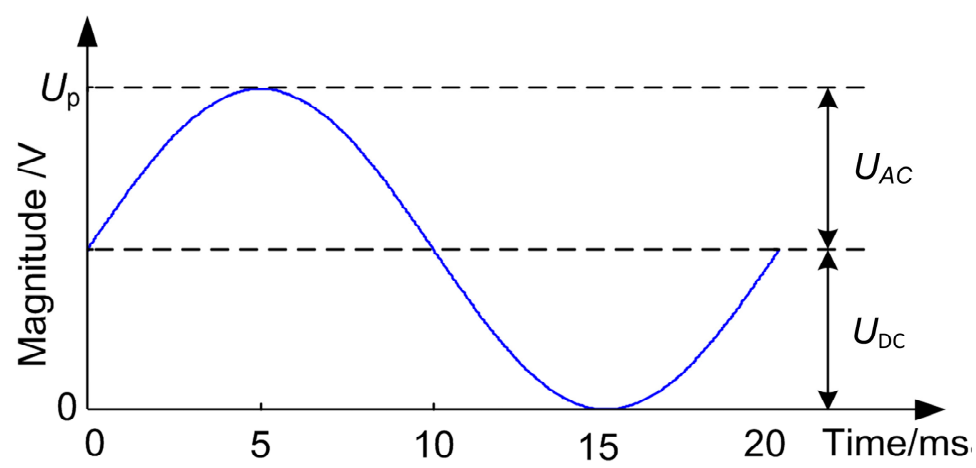

Figure 4. Typical pulsating direct current (DC) voltage waveform. 


\section{Breakdown Voltage of Thermally Aged OIP}

Figure 5 depicts the mean value of the breakdown voltage of OIP of different aging states with one standard deviation. In most cases, the AC breakdown voltage was the smallest, and pulsating DC $(r=1 / 5)$ breakdown voltage the greatest. No pronounced difference was found, however, in the magnitude of breakdown voltage among pulsating DC voltage $(r=1 / 5$ and $1 / 3)$ and DC voltage. The standard deviation of breakdown voltage at pulsating DC and DC voltage was greater than that at AC voltage, regardless of the thermal aging time or temperature. Nevertheless, those trends became inconspicuous when paper reached its end of life (taken as DP $=150-200[24,25]$ in this work), i.e., papers aged for 180 days at $120^{\circ} \mathrm{C}$ and 90 days at $130{ }^{\circ} \mathrm{C}$. In those aging states, minute differences were observed in breakdown voltage and corresponding standard deviation among the three types of voltage waveforms.

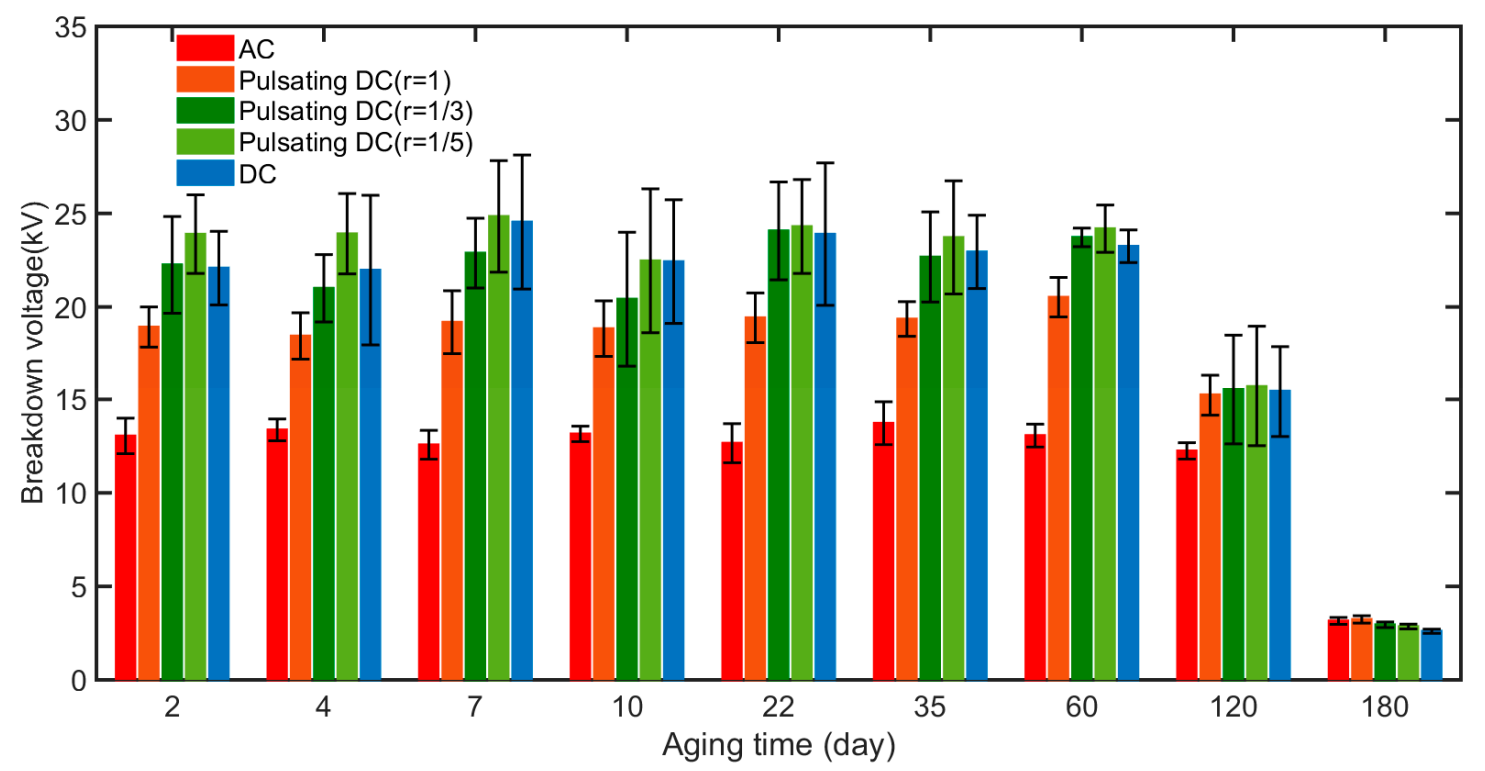

(a)

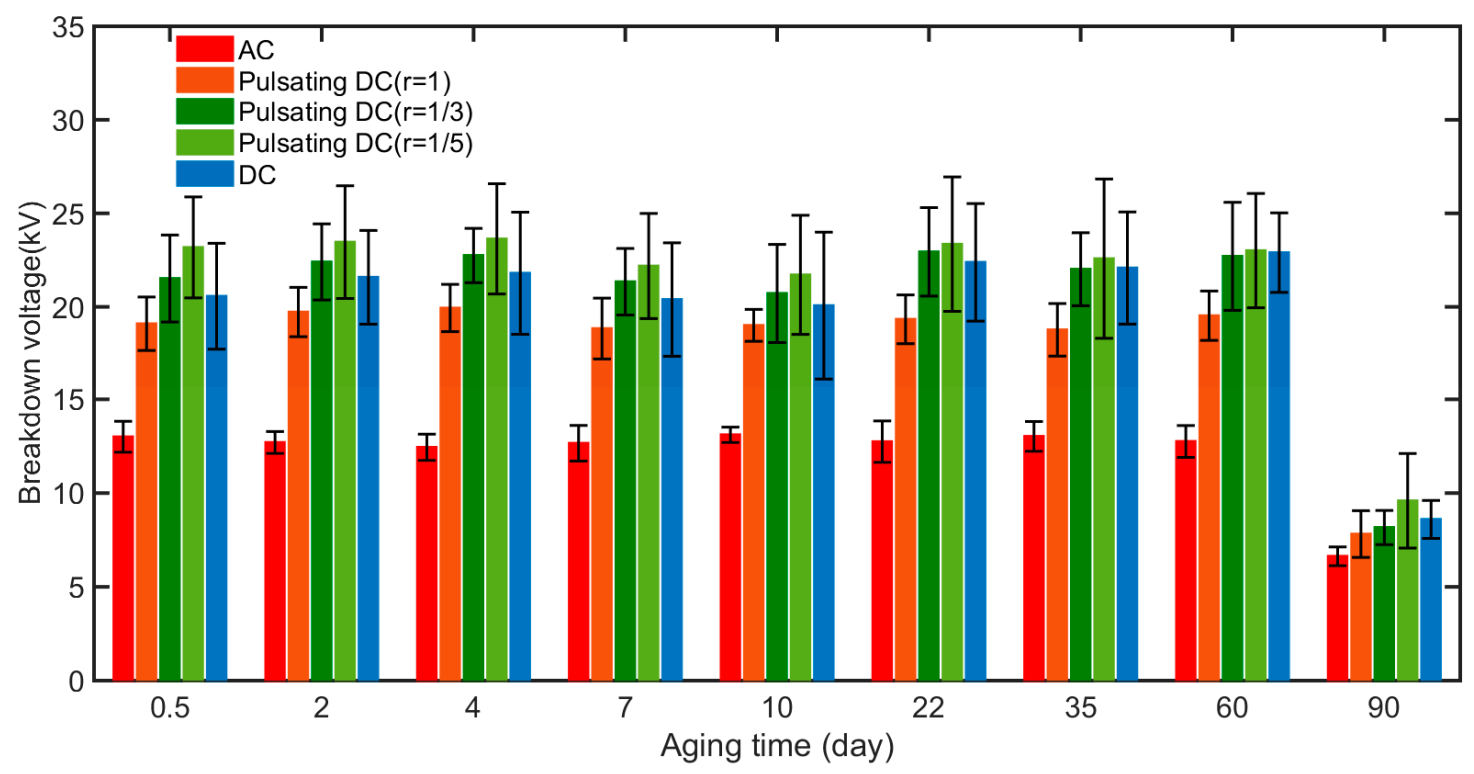

(b)

Figure 5. Breakdown voltage of oil-impregnated paper (OIP) after thermal aging with one standard deviation: (a) $120^{\circ} \mathrm{C}$; (b) $130{ }^{\circ} \mathrm{C}$. 
Figure 6 presents the changing tendency of breakdown voltage against aging time at different voltage waveforms. Before reaching its end of life, the breakdown voltage at pulsating DC voltage stayed in a relatively high level and did not necessarily decline. Instead, it exhibited some fluctuations with occasional increase versus the aging time regardless of the thermal aging temperature. The fluctuation in breakdown voltage at individual DC or AC voltage was also observed. Nevertheless, the changing tendency of breakdown voltage versus aging time at DC and pulsating DC voltage with small ripple factors $(r=1 / 5$ and 1/3) was opposite to the trend at AC voltage. This changing tendency was especially obvious for papers in the early or middle stage of aging, i.e., papers aged for no more than 35 days at $120^{\circ} \mathrm{C}$ and no more than 22 days at $130^{\circ} \mathrm{C}$. For example, in Figure $6 \mathrm{~b}$, from an aging time of four days to seven days, the AC breakdown voltage increased compared with that of the previous aging state, while the DC breakdown voltage and pulsating DC breakdown voltage with small ripple factors $(r=1 / 5$ and 1/3) decreased, though they all stayed at a relatively high level compared with that of unaged OIPs. All the above tendencies became inconspicuous when the OIP reached its end of life. It should be noted that the changing tendencies of the AC breakdown voltage at both temperatures were not in line with that obtained in reference [12], while they were similar to that in reference [21].

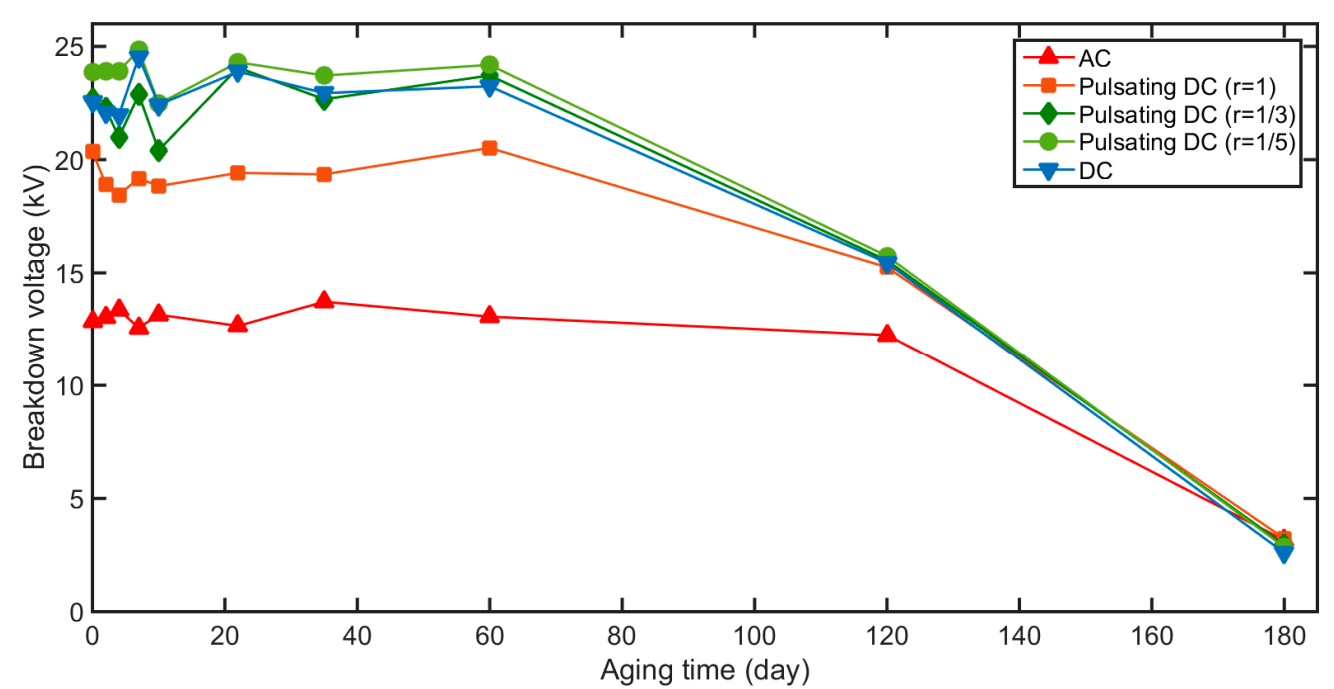

(a)

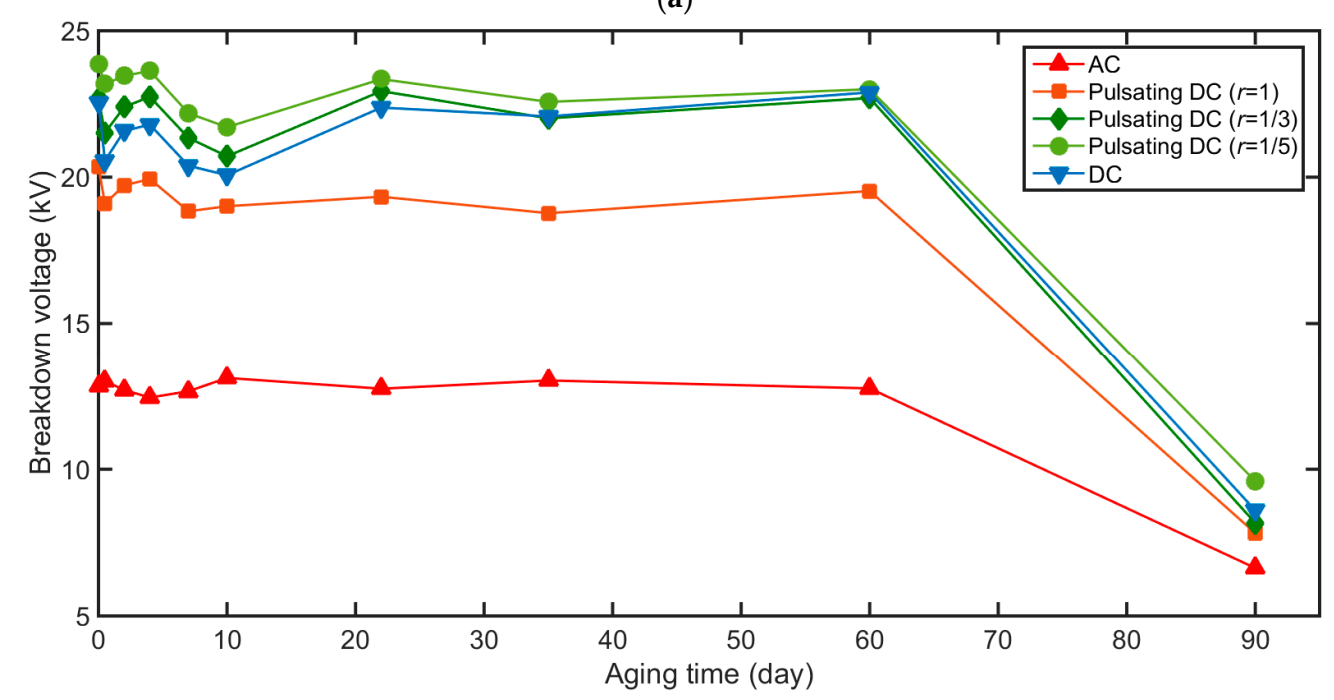

(b)

Figure 6. Breakdown voltage of OIP versus thermal aging time: $(\mathbf{a}) 120^{\circ} \mathrm{C} ;(\mathbf{b}) 130^{\circ} \mathrm{C}$. 


\section{Discussion}

\subsection{Difference in Magnitude of Breakdown Voltage at Different Voltage Waveforms}

In this section, the double-composite dielectric model is used to interpret the difference in the magnitude of breakdown voltage of OIP at pulsating DC voltage at each aging state from that at AC or DC voltage.

The insulating paper contains plenty of pores filled with gases. After degassing and impregnation, those pores are filled with insulating oil. The OIP can be equivalent to a composite dielectric with two layers, as modeled in Figure 7 , where $\varepsilon_{1}, \gamma_{1}, d_{1}$ and $\varepsilon_{2}, \gamma_{2}, d_{2}$ are the equivalent permittivity, conductivity, and thickness of the oil and paper, respectively; $R_{1}, R_{2}, C_{1}$, and $C_{2}$ are their equivalent resistance and capacitance, respectively; $U_{1}$ and $U_{2}$ are the voltages applied on insulating oil and insulating paper, respectively.

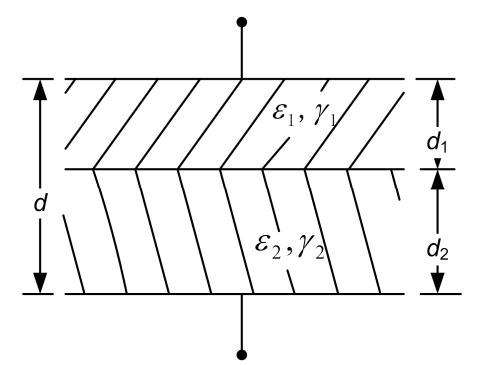

(a)

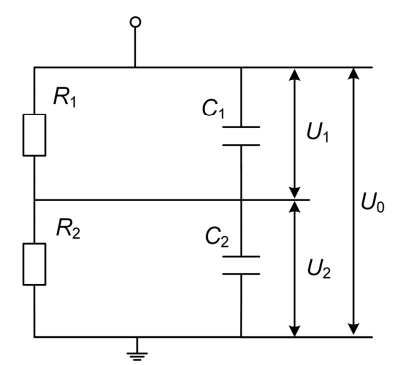

(b)

Figure 7. The (a) double-composite dielectric model and (b) corresponding equivalent circuit.

The electric field in the OIP is co-determined by permittivity of oil and paper at AC voltage while it is co-determined by the conductivity at DC voltage. Therefore, the electric field strength in oil and paper, i.e., $E_{\text {Oil }}$ and $E_{\text {Paper }}$, can be obtained at pulsating DC voltage, which are as follows $[19,26]$ :

$$
\begin{gathered}
E_{\text {Oil }}=U_{A C} \cdot \frac{\varepsilon_{2}}{\varepsilon_{2} d_{1}+\varepsilon_{1} d_{2}}+U_{D C} \cdot \frac{\gamma_{2}}{\gamma_{2} d_{1}+\gamma_{1} d_{2}} \\
E_{\text {Paper }}=U_{A C} \cdot \frac{\varepsilon_{1}}{\varepsilon_{2} d_{1}+\varepsilon_{1} d_{2}}+U_{D C} \cdot \frac{\gamma_{1}}{\gamma_{2} d_{1}+\gamma_{1} d_{2}}
\end{gathered}
$$

And the following relationship can be easily obtained:

$$
U_{0}=U_{1}+U_{2}=U_{A C}+U_{D C}
$$

For the convenience of later description, we define $E_{O b}$ and $E_{P b}$ as the dielectric breakdown strength of oil and paper, respectively.

For AC voltage, the electric field strength is inversely proportional to their permittivities for paper and oil. At room temperature, $\varepsilon_{1} / \varepsilon_{2}$ is about $1 / 2$. Therefore, most of the electric field strength is withstood by insulating oil. As $U_{0}$ increases, $E_{\text {Oil }}$ is always greater than $E_{\text {Paper }}$. Because $E_{\text {Paper }} / E_{\text {Oil }}$ is smaller than $E_{P b} / E_{O b}$, before the insulating oil breaks down, $E_{P a p e r}$ is always smaller than $E_{P b}$. $E_{O b}$ is much smaller than $E_{P b}$, so the oil breaks down prior to the paper, when $E_{O i l}$ reaches $E_{O b}$.

For DC voltage, the electric field strength is inversely proportional to their conductivities for oil and paper. Without considering the influence of moisture and other factors, $\gamma_{1} / \gamma_{2}$ is about 100 . Therefore, most of the electric filed strength is withstood by the paper. Because $E_{\text {Paper }} / E_{\text {Oil }}$ is greater than $E_{P b} / E_{O b}$, as $U_{0}$ increases, $E_{P a p e r}$ firstly reaches $E_{P b}$ before $E_{O i l}$ reaches $E_{O b}$. The paper then breaks down prior to the oil. Because $E_{P b}$ at DC voltage is a lot greater than $E_{O i l}$, the corresponding breakdown voltage exceeds that at $\mathrm{AC}$ voltage. 
For pulsating $D C$ voltage, Equations (2) and (3) can be rewritten as follows using Equations (1) and (4):

$$
\begin{gathered}
E_{\text {Oil }}=\frac{U_{0}}{1+r} \cdot\left(\frac{r \varepsilon_{2}}{\varepsilon_{2} d_{1}+\varepsilon_{1} d_{2}}+\frac{\gamma_{2}}{\gamma_{2} d_{1}+\gamma_{1} d_{2}}\right) \approx \frac{U_{0}}{1+r} \cdot\left(\frac{2 r}{2 d_{1}+d_{2}}+\frac{1}{d_{1}+100 d_{2}}\right) \\
E_{\text {Paper }}=\frac{U_{0}}{1+r} \cdot\left(\frac{r \varepsilon_{1}}{\varepsilon_{2} d_{1}+\varepsilon_{1} d_{2}}+\frac{\gamma_{1}}{\gamma_{2} d_{1}+\gamma_{1} d_{2}}\right) \approx \frac{U_{0}}{1+r} \cdot\left(\frac{r}{2 d_{1}+d_{2}}+\frac{100}{d_{1}+100 d_{2}}\right)
\end{gathered}
$$

When $r$ is very small, i.e., the DC component in pulsating DC voltage is dominant, which is similar to that at DC voltage- the paper breaks down prior to the oil. When $r$ is very large, i.e., the AC component in pulsating DC voltage is dominant, which is similar to the situation for AC voltage, and the oil breaks down prior to the paper.

Suppose the DC $(r=0)$ breakdown voltage of the OIP is $U_{D}$. When $r$ increases from 0 to infinite, Equations (7) and (8) are permanently satisfied, i.e., the value of Equation (7) is always greater than 0, while the value of Equation (8) is always smaller than 0 . In other words, the electric field strength in paper decreases while that in oil increases. If the increment in voltage applied to oil is greater than the decrease in voltage applied to paper, then the breakdown voltage increases and exceed $U_{D}$. Note, however, that the breakdown voltage does not necessarily increase all the time, as $r$ increases from 0 to infinite, or the AC breakdown voltage is the greatest. It is actually the smallest. Therefore, it is obvious that an $r$ exists for the breakdown voltage to reach a maximum value, and it is greater than the DC breakdown voltage. The maximum value is obtained when Equation (9) is satisfied.

$$
\begin{gathered}
\frac{d E_{\text {Oil }}}{d r}=\frac{199 d_{2} U_{0}}{(1+r)^{2}\left(2 d_{1}+d_{2}\right)\left(d_{1}+100 d_{2}\right)}>0 \\
\frac{d E_{\text {Paper }}}{d r}=\frac{-199 d_{1} U_{0}}{(1+r)^{2}\left(2 d_{1}+d_{2}\right)\left(d_{1}+100 d_{2}\right)}<0 \\
\frac{E_{\text {Oil }}}{E_{\text {Paper }}}=\frac{E_{O b}}{E_{P b}}
\end{gathered}
$$

In other words, the breakdown voltage reaches its maximum value when the paper and oil break down at the same time. The corresponding $r$ can be obtained with Equations (5), (6), and (9), and it is as follows:

$$
r \approx \frac{\left(E_{P b} / E_{O b}-100\right)\left(2 d_{1} / d_{2}+1\right)}{\left(1-2 E_{P b} / E_{O b}\right)\left(d_{1} / d_{2}+100\right)}
$$

It is evident from Equation (10) that $r$ is dependent on $d_{1}, d_{2}, E_{O b}$, and $E_{P b}$. Additionally, $E_{O b}$ and $E_{P b}$ are not constants for oil and paper of different thicknesses and different voltage waveforms [20]. In other words, it depends on the interaction between $d_{1} / d_{2}$ and $E_{P b} / E_{O b}$ when the breakdown voltage of OIP reaches its maximum value. In this experiment, the maximum value was observed for an $r$ of $1 / 5$, except the insulating paper that reached its end of life when few differences existed in the breakdown voltage at the three types of voltage waveforms.

\subsection{Possible Influencing Factors for Variation of Breakdown Voltage Versus Aging Time}

In this section, the variation of breakdown voltage versus aging time is analyzed, including the opposite changing tendencies between AC voltage, and pulsating DC voltage with small ripple factors $(r=1 / 5$ and $1 / 3)$ and DC voltage. Possible influencing factors such as DP, moisture content of paper and oil absorption associated with the pores and cracks of aged paper are investigated. 


\subsubsection{DP of Paper}

Figure 8 presents the DP of the paper. The first-order kinetic model was used to fit the DP versus the aging time, which is shown in Equation (11) as follows [27]:

$$
\frac{1}{P_{t}}-\frac{1}{P_{0}}=k t
$$

where $P_{0}$ and $P_{t}$ are the DP of unaged paper and paper aged for an duration of $t$, respectively; $k$ is a constant. DP decreased dramatically at both aging temperatures, whereas it decreased relatively slowly when approaching about 500. Note that DP of paper aged for 180 days at $120{ }^{\circ} \mathrm{C}$, and for 90 days at $130^{\circ} \mathrm{C}$, reached a level less than 250 . No clear correlation was found, however, between DP and the breakdown voltage. Even when the DP decreased from 1265 to less than 400, no marked reduction in breakdown voltage was observed. Therefore, the decrease in DP had no reason to be considered for the small variation of breakdown voltage of OIP, and in turn the breakdown voltage could not be taken as an indicator of the aging state of paper, which was in accordance with [22]. However, this was not applicable to the life-end stage of the OIP, because the DP reached a seriously small level. The structural damage of paper at this stage together with the high level of moisture content was significant enough to contribute to the sudden decrease of breakdown voltage. This was not in line with publication [12] mainly because of the difference in the moisture level and paper structural damage.

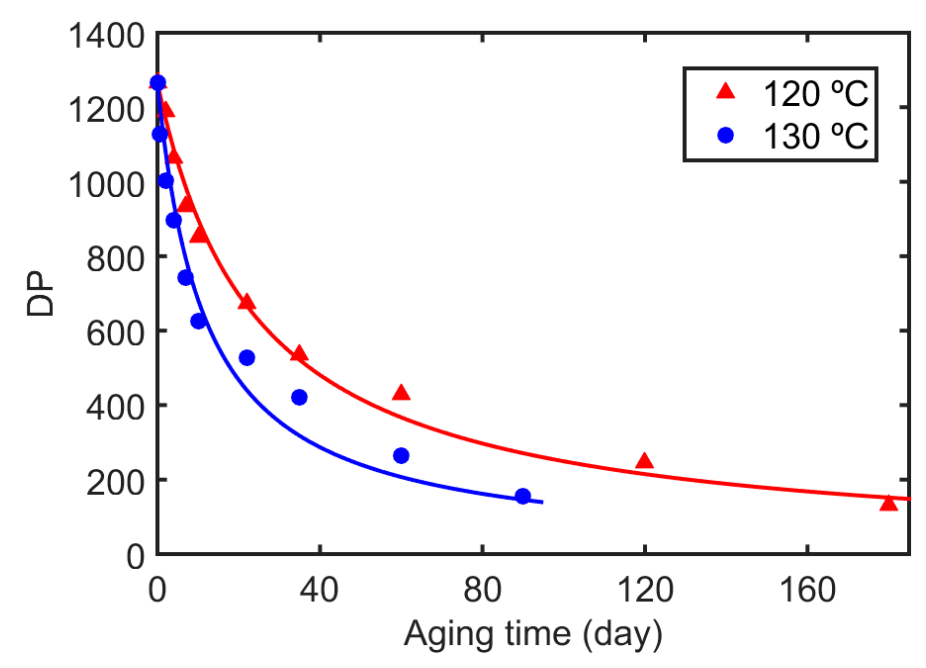

Figure 8. DP of aged paper.

\subsubsection{Moisture Content}

Figure 9 shows the moisture content in OIP. It fluctuated during the aging process and increased sharply when the paper nearly reached its end of life. Moisture content was considered to influence the breakdown strength of paper [28]. That might be the reason why the obtained results were not all in line with those obtained in [12], as the moisture content for some of the aged papers were relatively higher than that in [12]. However, it could not explain why some OIPs with a relative high level of moisture content had a relatively high AC breakdown voltage. For example, for paper subject to thermal aging for two and 60 days at $120^{\circ} \mathrm{C}$ and for two, seven, and 10 days at $130{ }^{\circ} \mathrm{C}$, the breakdown voltage, especially the AC breakdown voltage, did not decline much, or even increased compared with that of unaged paper, and was even higher than some other papers whose moisture level was relatively low. This implies that there could be some other factors offsetting the influence of moisture content on AC breakdown voltage of those thermally aged paper. 


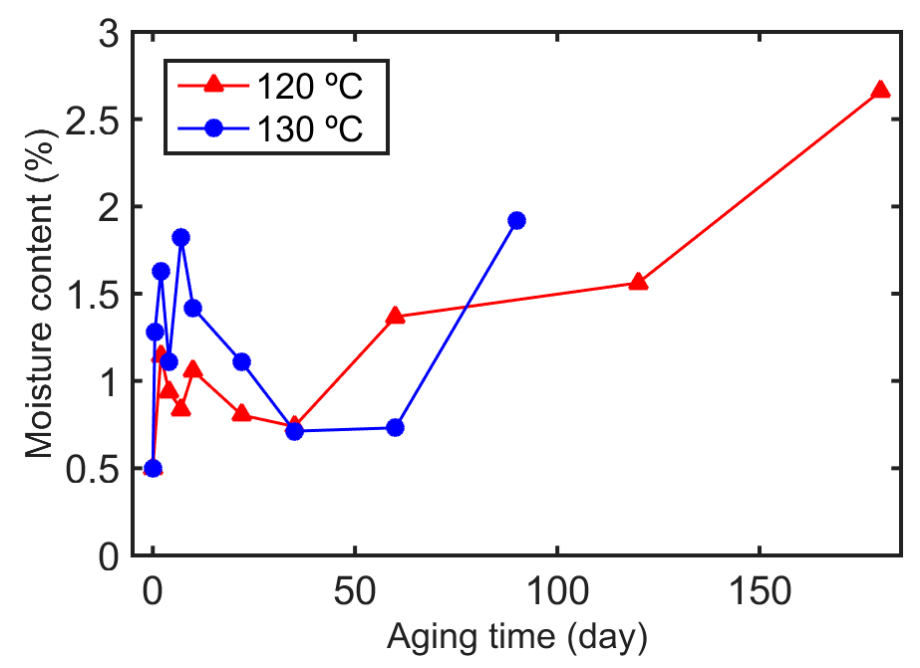

Figure 9. Moisture content of OIP.

\subsubsection{Oil Absorption Ability of Paper Associated with Pores and Cracks}

Insulating paper consists of large numbers of cellulose fibers and it has a lot of pores, the diameter of which ranges from tens of nanometers to thousands of nanometers. In this paper, the mesoporous distribution of insulating paper was measured with nitrogen gas adsorption and desorption method, and its macropores were observed with SEM to associate the oil absorption ability with some of the changing tendency of the breakdown voltage. For simple discussion and analysis in this paper, papers aged at $130{ }^{\circ} \mathrm{C}$ are selected as an example, and are the same as those aged at $120^{\circ} \mathrm{C}$.

The nitrogen gas adsorption and desorption measurements were conducted to examine the porous nature of the insulating paper. The pore-size distribution and pore volume were obtained following the Barrett-Joyner-Halenda (BJH) method [29], and the specific surface area was obtained with the Brunauer-Emmett-Teller (BET) method [30]. Figure 10 shows the typical nitrogen gas adsorption and desorption isotherm of insulating paper.

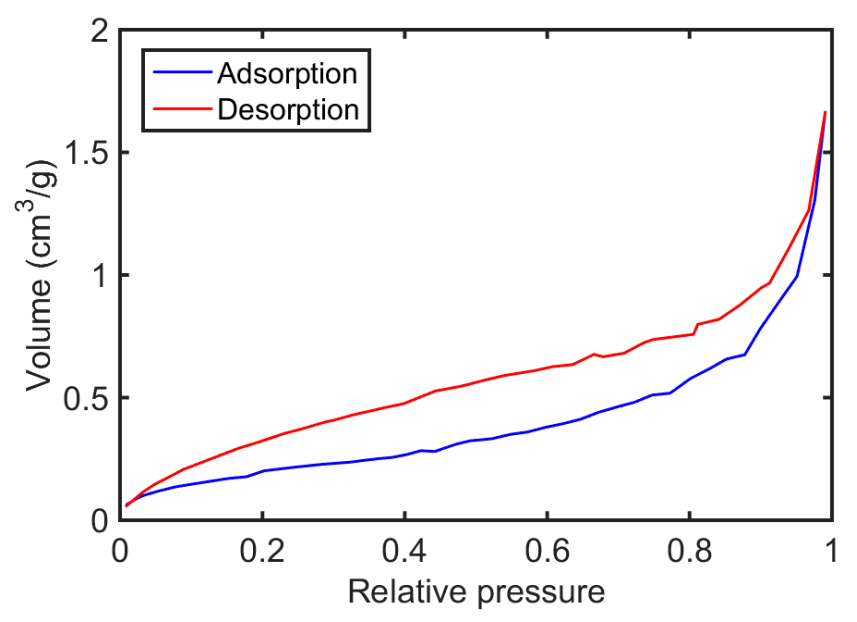

Figure 10. Typical nitrogen adsorption and desorption isotherm of insulating paper.

The $\mathrm{BJH}$ analyses showed that the insulating paper exhibited no pore sizes of less than 15 nanometers, and there were various most probable pore sizes for papers of different aging states, as shown in Figure 11. For OIPs with aging time of 0, 2, 7, 10, 22, and 90 days, they had marked probable pore sizes, and the corresponding peak value of $\mathrm{d} V / \mathrm{d} D$ was greater than that of other aged OIPs, which indicates they had large pore size and volume, which is consistent with the results presented 
in Figure 12. The BET specific surface area of insulating paper of different aging states is presented in Figure 13. It exhibited a fluctuation during the thermal aging process, following almost the same variation tendency with that of pore volume.

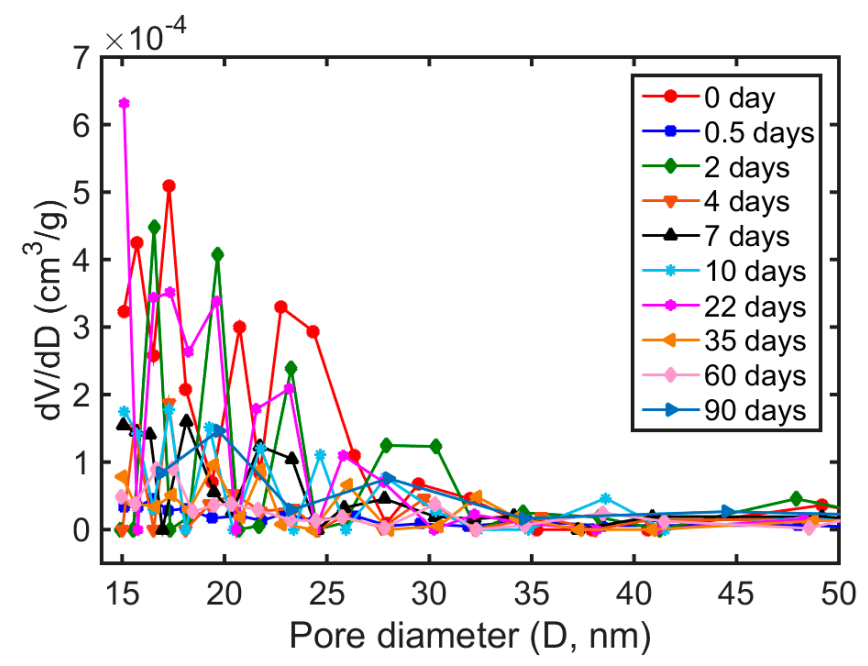

Figure 11. Pore distribution of paper thermally aged for various durations at $130{ }^{\circ} \mathrm{C}$.

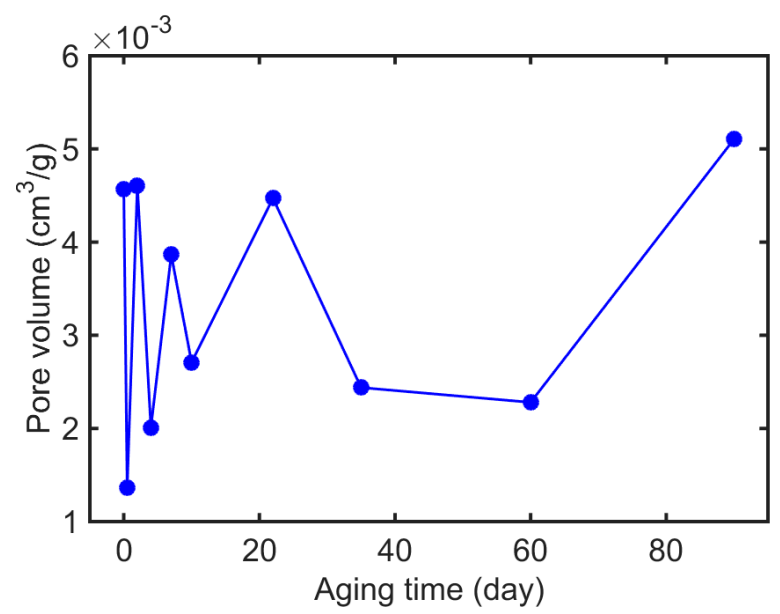

Figure 12. Pore volume of paper thermally aged for various durations at $130{ }^{\circ} \mathrm{C}$.

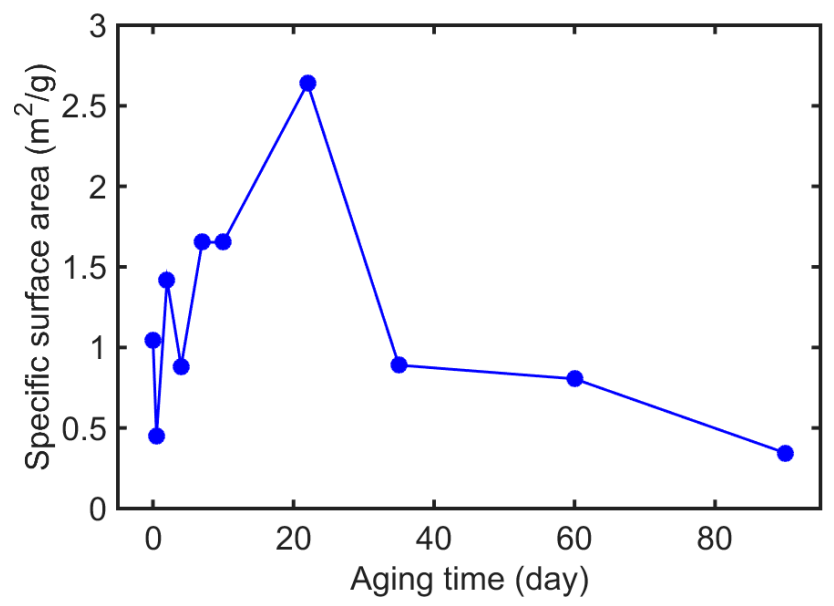

Figure 13. Specific surface area of paper thermally aged for various durations at $130^{\circ} \mathrm{C}$. 
Figure 14 shows typical SEM images of insulating paper thermally aged for various durations at $130^{\circ} \mathrm{C}$. Macropores or cracks with a diameter of several micrometers began to appear in insulating paper after 22 days of thermal aging. The diameter of pores and cracks exhibited an increasing tendency along with the increase of thermal aging time.

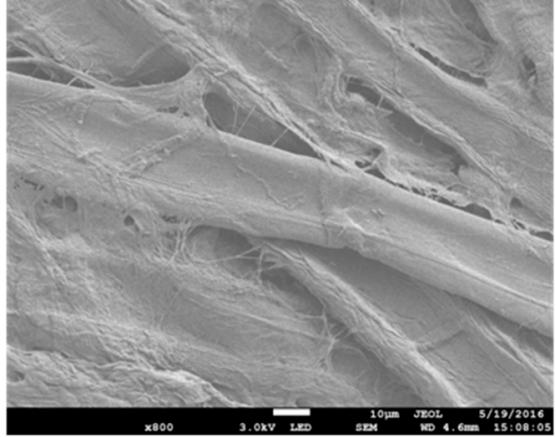

(a)

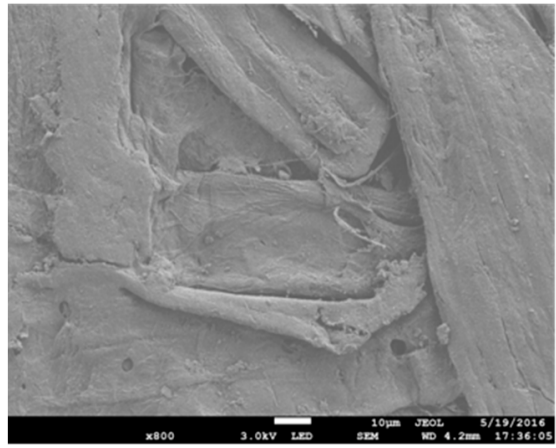

(c)

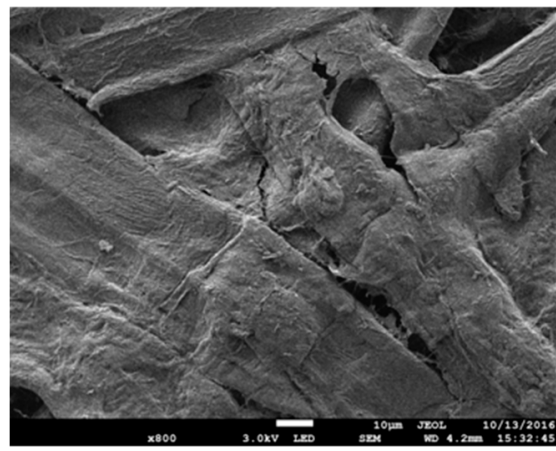

(e)

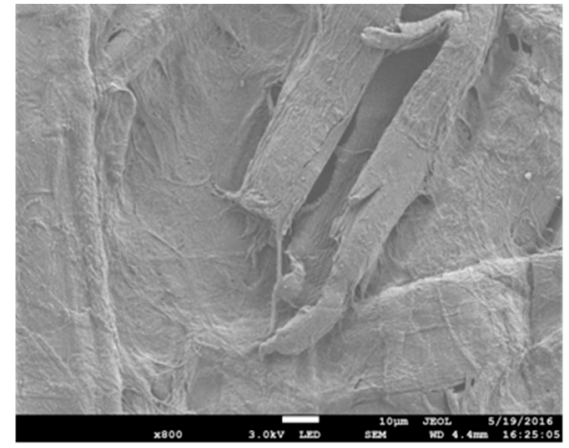

(b)

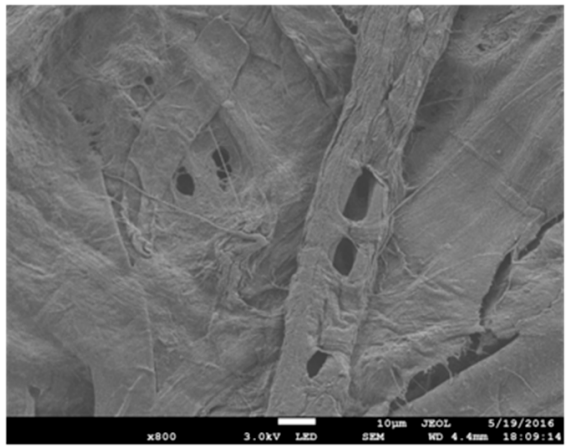

(d)

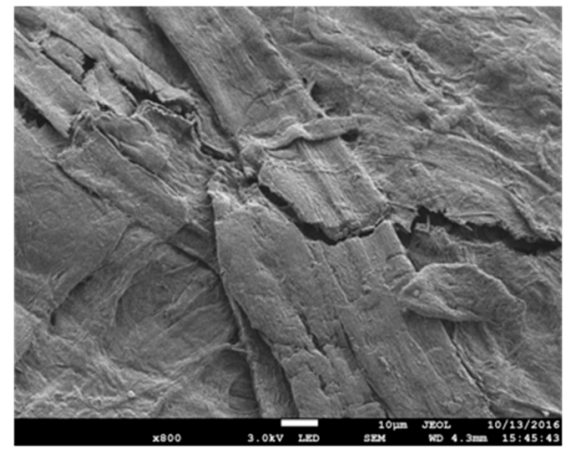

(f)

Figure 14. Scanning electron microscopy (SEM) images of paper thermally aged for various durations at $130{ }^{\circ} \mathrm{C}$. (a) 0 day; (b) 10 days; (c) 22 days; (d) 35 days; (e) 60 days; (f) 90 days.

The increased oil absorption associated with the pores and cracks of paper had different effects on the breakdown voltage of OIP at DC and AC voltage, which is discussed below.

As is well-known, the relation between the electric field strength $E_{(l)}$ and the voltage applied to the OIP sample $U_{0}$ can be expressed as [12]:

$$
U_{0}=\int E_{(l)} d l
$$


where $l$ is the distance at the direction of electric field. For simplicity, $E_{O i l}$ and $E_{\text {Paper }}$ are considered to be uniform. When the applied voltage is AC voltage, the relationship between the both can be written as [22]:

$$
\frac{E_{\text {Oil }}}{E_{\text {Paper }}}=\frac{\varepsilon_{2}}{\varepsilon_{1}}
$$

Combining (12) and (13) yields the electric field in oil and paper as [12]:

$$
\begin{aligned}
& E_{\text {Oil }}=\frac{U_{0}}{\left(1-\frac{\varepsilon_{1}}{\varepsilon_{2}}\right) l_{0}+\frac{\varepsilon_{1}}{\varepsilon_{2}} l} \\
& E_{\text {Paper }}=\frac{U_{0}}{\left(\frac{\varepsilon_{2}}{\varepsilon_{1}}-1\right) l_{o}+l}
\end{aligned}
$$

where $l_{o}$ is the total equivalent thickness of oil along the electric field. For the case that more oil is absorbed by the paper, i.e., the increased $l_{0}$, it causes the decrease of electric field strength, this should obviously create better electric field distribution in the OIP. Consequently, the breakdown voltage increases.

In the case of applying a DC voltage, (13) can be rewritten as [6]:

$$
\frac{E_{\text {Oil }}}{E_{\text {Paper }}}=\frac{\gamma_{2}}{\gamma_{1}}
$$

Combining (12) and (16), yields the electric field in oil and paper as [12]:

$$
\begin{aligned}
& E_{\text {oil }}=\frac{U_{0}}{\left(1-\frac{\gamma_{1}}{\gamma_{2}}\right) l_{o}+\frac{\gamma_{1}}{\gamma_{2}} l} \\
& E_{\text {Paper }}=\frac{U_{0}}{\left(\frac{\gamma_{2}}{\gamma_{1}}-1\right) l_{o}+l}
\end{aligned}
$$

When more oil is contained in the paper, i.e., $l_{0}$ is increased, the electric field in oil and paper increase resultantly. This leads to a decreased breakdown voltage. It is therefore seen that the application of DC voltage make the breakdown voltage develop in an opposite fashion to that of AC voltage.

For the OIP samples aged for less than 35 days, the increased pore volume and specific surface area were expected to have a higher capacity of oil absorption. This would result in quite different AC and DC breakdown voltage values upon the case that more oil would be absorbed into the insulating paper. This should account for that the AC breakdown voltage of OIPs aged for two, seven, 10, and 22 days did not drop much, or even increased a bit compared with that of unaged OIPs, although the moisture content in some of those OIP samples remained relatively high at around $1.8 \%$. However, as the oil absorbed had opposite effects on breakdown voltage at AC and DC voltage, the changing tendencies of DC voltage and pulsating DC voltage with small ripple factors $(r=1 / 5$ and $1 / 3)$ were different from that of AC voltage. For example, from an aging time of four days to seven days, the AC breakdown voltage increased compared with that of its previous aging state while the DC breakdown voltage and pulsating DC breakdown voltage with small ripple factors $(r=1 / 5$ and $1 / 3)$ decreased.

For the OIP samples aged for 35 and 60 days, mesopores pore size and volume in insulating paper were not the dominant factors influencing breakdown voltage. Instead, the influence of macropores or cracks of cellulose fibers were considered, as shown in Figure 14. They were filled with oil, improving the electric field distribution in OIP samples at AC voltage. Damage to paper structure might reduce the breakdown voltage, whereas the improvement in electric field distribution somewhat balanced this effect. Consequently, the AC breakdown voltage showed limited reduction compared with that of 
unaged OIPs. However, the breakdown voltage at pulsating DC with small ripple factors $(r=1 / 5$ and $1 / 3$ ) and DC voltage exhibited a greater decrease compared with that of unaged OIPs, as the oil in paper had adverse effects on it.

For the OIP samples aged for 90 days, DP of paper was very small (around 160) and the structure of paper was seriously damaged in this state. Therefore, the breakdown voltage reduced sharply, regardless of the pores and cracks that were filled with oil. In this aging state, the damage to paper structure became the dominant factor influencing the breakdown voltage. It should also be noted that the moisture content was very high (about $2 \%$ ) at this aging state, which also contributed to the decrease of breakdown voltage.

\section{Conclusions}

This paper investigates the breakdown voltage and its influencing factors of thermally aged OIP at pulsating DC voltage. The main conclusions are summarized as follows.

Breakdown voltage at pulsating DC voltage and DC voltage was far greater and had a greater standard deviation than AC breakdown voltage. It was co-determined by the electric field distribution in paper and oil, and their breakdown strengths. The analysis results by the double-composite dielectric model showed that a ripple factor $r$ existed for the breakdown voltage to reach its maximum value. The difference in magnitude of breakdown voltage among pulsating DC $(r=1 / 5$ and $1 / 3)$ and DC voltage, however, was not so pronounced.

The breakdown voltage of aged OIP at pulsating DC voltage fluctuated during the thermal aging process as the AC breakdown voltage did, but showed a somewhat opposite changing tendency, especially for the breakdown voltage at pulsating DC voltage with small ripple factors $(r=1 / 5$ and $1 / 3$ ) in the early and middle stage of aging. The moisture content, oil absorption ability associated with pores and cracks of paper, and the damage to paper structure all contributed to the variation of the breakdown voltage versus aging time with different weights of importance as the aging state of paper varied. For OIPs in the early or middle stage of aging, the variation in breakdown voltage versus aging time was considered to be influenced by moisture content and the oil absorption related to the mesopore volume of paper. The oil filled the pores and improved the electric field distribution at AC voltage, and thus had a positive effect on the AC breakdown voltage, while it had an adverse effect on the DC breakdown voltage. Therefore, the breakdown voltage at pulsating DC voltage with small ripple factors $(r=1 / 5$ and 1/3) and DC voltage showed an opposite changing tendency compared with that at AC voltage. For OIPs in the middle-late stage of aging, the macropores or cracks between cellulose fibers rather than the mesopores were considered to have influenced the breakdown voltage of OIP together with moisture content and structural damage of paper. For OIPs that reached its end of life, the damage to the paper structure and the high level of moisture were the dominant influencing factors. Both factors resulted in the sharp decrease of breakdown voltage at the three types of voltage waveforms.

Acknowledgments: The authors thank the National Natural Science Foundation of China (Grant No. 51425702) and the 111 Project of China (Grant No. B08036) for the financial support provided.

Author Contributions: The research work presented in this paper was collaboratively conducted by all authors. Feipeng Wang and Jian Li designed the experiment; Jing Zhang carried out the experiments with Hehuan Ran and Xudong Li; Jing Zhang analyzed the test results with Feipeng Wang and Qiang Fu; Jing Zhang wrote this paper; Feipeng Wang revised the manuscript.

Conflicts of Interest: The authors declare no conflict of interest.

\section{References}

1. Kohtoh, M.; Kaneko, S.; Okabe, S.; Amimoto, T. Aging effect on electrical characteristics of insulating oil in field transformer. IEEE Trans. Dielectr. Electr. Insul. 2009, 16, 1698-1706. [CrossRef]

2. Prevost, T.A.; Oommen, T.V. Cellulose insulation in oil-filled power transformers: Part I-history and development. IEEE Electr. Insul. Mag. 2006, 22, 28-35. [CrossRef] 
3. Oommen, T.V.; Prevost, T.A. Cellulose insulation in oil-filled power transformers: Part II maintaining insulation integrity and life. IEEE Electr. Insul. Mag. 2006, 22, 5-14. [CrossRef]

4. Saha, T.K. Review of modern diagnostic techniques for assessing insulation condition in aged transformers. IEEE Trans. Dielectr. Electr. Insul. 2003, 10, 903-917. [CrossRef]

5. Bao, L.; Li, J.; Zhang, J.; Li, X.; Li, X. Influences of temperature on partial discharge behavior in oil-paper bounded gas cavity under pulsating DC voltage. IEEE Trans. Dielectr. Electr. Insul. 2016, 23, 1482-1490. [CrossRef]

6. Li, J.; He, Z.; Grzybowski, S. Electrical aging lifetime model of oil-impregnated paper under pulsating DC voltage influenced by temperature. IEEE Trans. Dielectr. Electr. Insul. 2013, 20, 1992-1997. [CrossRef]

7. Zhou, Y.X.; Jin, F.B.; Huang, M.; Le, T.H.; Huang, J.W.; Liu, Z.H.; Lu, L.C. Effects of thermal aging on creepage discharge in oil- impregnated pressboard under combined AC-DC voltage. IEEE Trans. Dielectr. Electr. Insul. 2015, 22, 2737-2746. [CrossRef]

8. Qi, B.; Zhao, X.; Li, C.; Wu, H. Electric field distribution in oil-pressboard insulation under AC-DC combined voltages. IEEE Trans. Dielectr. Electr. Insul. 2016, 23, 1935-1941. [CrossRef]

9. Nazemi, M.H.; Hinrichsen, V. Experimental investigations on partial discharge characteristics of water droplets on polymeric insulating surfaces at AC, DC and combined AC-DC voltages. IEEE Trans. Dielectr. Electr. Insul. 2015, 22, 2261-2270. [CrossRef]

10. Qi, B.; Wei, Z.; Li, C.; Gao, Y.; Zhang, X. Influences of Different Ratios of AC-DC Combined Voltage on Internal Gas Cavity Discharge in Oil-Pressboard Insulation. IEEE Trans. Power Deliv. 2016, 31, 1026-1033. [CrossRef]

11. Abdelmalik, A.A. Analysis of thermally aged insulation paper in a natural ester-based dielectric fluid. IEEE Trans. Dielectr. Electr. Insul. 2015, 22, 2408-2414. [CrossRef]

12. Sun, P.; Sima, W.; Yang, M.; Wu, J. Influence of thermal aging on the breakdown characteristics of transformer oil impregnated paper. IEEE Trans. Dielectr. Electr. Insul. 2016, 23, 3373-3381. [CrossRef]

13. Huaqiang, L.; Yaning, Z.; Lisheng, Z.; Qinxue, Y.; Xu, L.; Guangqi, L.; Mori, S.; Yamada, S. The DC breakdown of mineral insulating oil and oil-pressboard. In Proceedings of the 2013 Annual Report Conference on Electrical Insulation and Dielectric Phenomena, Shenzhen, China, 20-23 October 2013; pp. 929-931.

14. Lianwei, B.; Jian, L.; Jinzhuang, L.; Zhiman, H.; Yan, W. Electrical breakdown characteristics of oil-paper insulation under pulsating voltage. In Proceedings of the 2012 International Conference on High Voltage Engineering and Application (ICHVE), Shanghai, China, 17-20 September 2012; pp. 484-488.

15. Wang, Z.; Pang, L.; Wang, T.; Yang, H.; Zhang, Q.; Li, J. Breakdown characteristics of oil-paper insulation under lightning impulse waveforms with oscillations. IEEE Trans. Dielectr. Electr. Insul. 2015, 22, 2620-2627. [CrossRef]

16. Vandermaar, A.J.; Wang, M.; Neilson, J.B.; Srivastava, K.D. The electrical breakdown characteristics of oil-paper insulation under steep front impulse voltages. IEEE Trans. Power Deliv. 1994, 9, 1926-1935. [CrossRef]

17. Sima, W.; Hua, J.; Yang, M.; Wu, J. Impact of time parameters of lightning impulse on the breakdown characteristics of oil paper insulation. High Volt. 2016, 1, 18-24. [CrossRef]

18. Sima, W.; Wu, J.; Sun, P.; Yang, M.; Hua, J. Breakdown characteristics of oil-impregnated paper and influential factors for damped alternating oscillation waveforms. IEEE Trans. Dielectr. Electr. Insul. 2016, 23, 2079-2087. [CrossRef]

19. Bao, L.; Li, J.; Zhang, J.; Li, X. Electrical Breakdown Properties of Oil-paper Insulation under Pulsating Voltage Influenced by Temperature. J. Electr. Eng. Technol. 2016, 11, 1735-1743. [CrossRef]

20. Chen, Q.; Chi, M.; Gao, Y.; Wei, X.; Wang, Y.; Zhang, S. Breakdown Characteristics and Its Mathematical Model of Oil-pressboard Insulation Under Compound Electric Field. Proc. CSEE 2013, 33, 170-176.

21. Liao, R.; Hao, J.; Chen, G.; Ma, Z.; Yang, L. A comparative study of physicochemical, dielectric and thermal properties of pressboard insulation impregnated with natural ester and mineral oil. IEEE Trans. Dielectr. Electr. Insul. 2011, 18, 1626-1637. [CrossRef]

22. Tang, C.; Liao, R.; Huang, F.; Y, L.; Zhu, M. The Breakdown Voltage of Power Transformer Insulation Paper After Thermal Aging. Trans. China Electrotech. Soc. 2010, 25, 1-8.

23. Electric Strength of Insulating Materials. Test Methods, Tests at Power Frequencies; IEC 60243:2013; BSI: London, UK, 2013. 
24. Shroff, D.H.; Stannett, A.W. A review of paper aging in power transformers. IEE Proc. C Gener. Transm. Distrib. 1985, 132, 312-319. [CrossRef]

25. Emsley, A.M.; Heywood, R.J.; Ali, M.; Xiao, X. Degradation of cellulosic insulation in power transformers. Part 4: Effects of ageing on the tensile strength of paper. IEE Proc. Sci. Meas. Technol. 2000, 147, 285-290. [CrossRef]

26. Takahashi, E.; Tsutsumi, Y.; Okuyama, K.; Ogata, F. Partial discharge characteristics of oil-immersed insulation systems under DC, combined AC-DC and DC reversed polarity voltage. IEEE Trans. Power Appar. Syst. 1976, 95, 411-420. [CrossRef]

27. Emsley, A. The kinetics and mechanisms of degradation of cellulosic insulation in power transformers. Polym. Degrad. Stab. 1994, 44, 343-349. [CrossRef]

28. Oommen, T.V. Moisture Equilibrium Charts for Transformer Insulation Drying Practice. IEEE Trans. Power Apper. Syst. 1984, PAS-103, 3062-3067. [CrossRef]

29. Tang, Y.; Wu, D.; Chen, S.; Zhang, F.; Jia, J.; Feng, X. Highly reversible and ultra-fast lithium storage in mesoporous graphene-based $\mathrm{TiO}_{2} / \mathrm{SnO}_{2}$ hybrid nanosheets. Energy Environ. Sci. 2013, 6, 2447-2451. [CrossRef]

30. Li, Y.; Li, Z.; Shen, P.K. Simultaneous Formation of Ultrahigh Surface Area and Three-Dimensional Hierarchical Porous Graphene-Like Networks for Fast and Highly Stable Supercapacitors. Adv. Mater. 2013, 25, 2474-2480. [CrossRef] [PubMed]

(C) 2017 by the authors. Licensee MDPI, Basel, Switzerland. This article is an open access article distributed under the terms and conditions of the Creative Commons Attribution (CC BY) license (http://creativecommons.org/licenses/by/4.0/). 